\title{
Corrigendum \\ Relapse Prevention in Schizophrenia and Schizoaffective Disorder with Risperidone Long-Acting Injectable vs Quetiapine: Results of a Long-Term, Open-Label, Randomized Clinical Trial
}

Wolfgang Gaebel, Andreas Schreiner, Paul Bergmans, Rosario de Arce, Frédéric Rouillon, Joachim Cordes, Lars Eriksson and Enrico Smeraldi

Neuropsychopharmacology (20II) 36, 548; doi:10.1038/npp.2010.206; published online 17 November 2010

Correction to: Neuropsychopharmacology (2010) 35, 2367-2377; doi:10.1038/npp.2010.111; published online 4 August 2010

In this article, the authors would like to apologize for an error inadvertently introduced into the paper. During pre-marketing clinical studies, reactions that presented with signs and symptoms consistent with olanzapine overdose were reported in patients following an injection of olanzapine pamoate. These reactions occurred in $<0.1 \%$ of the injections and in approximately $2 \%$ of patients, according to the EU SPC, for olanzapine pamoate. ${ }^{1,2}$ In the EU SPC, at the moment the manuscript was written, post-injection delirium syndrome (PDSS) occurred in approximately $1 \%$ of patients. In the introduction section on page 2 , we inadvertently stated that PDSS occurred after about $1 \%$ of olanzapine pamoate injections (Citrome, 2009). The authors intended to state that PDSS occurs in about
$1 \%$ of patients receiving olanzapine pamoate injections. We now have updated the note according to the EU SPC, stating that PDSS occurs in $<0.1 \%$ of olanzapine pamoate injections and in about $2 \%$ of patients.

\footnotetext{
${ }^{1}$ http://www.ema.europa.eu/ema/index.jsp?curl=pages/ medicines/human/medicines/000890/human_med_001188.jsp\& murl $=$ menus $/$ medicines $/$ medicines.jsp\&mid $=$ WCOb01ac0580 01d124\&jsenabled $=$ true
}

${ }^{2}$ http://www.ema.europa.eu/docs/en_GB/document_library/ EPAR_-_Product_Information/human/000890/WC500054429.pdf

Citrome L (2009). Olanzapine pamoate: a stick in time? A review of the efficacy and safety profile of a new depot formulation of a second-generation antipsychotic. Int J Clin Pract 63: 140-150. 